\title{
Menaquinone-4 modulates the expression levels of calcification-associated factors to inhibit calcification of rat aortic vascular smooth muscle cells in a dose-dependent manner
}

\author{
LIWEN CUI, JINSHENG XU, JUNXIA ZHANG, MUQING ZHANG, SHENGLEI ZHANG and YALING BAI \\ Department of Nephrology, The Fourth Hospital of Hebei Medical University, Shijiazhuang, Hebei 050011, P.R. China
}

Received March 25, 2016; Accepted March 6, 2017

DOI: $10.3892 /$ etm.2018.6535

\begin{abstract}
Vascular calcification (VC) caused by chronic kidney disease (CKD)-mineral and bone disorder is a common complication of CKD. Recent studies have demonstrated that menaquinone-4 (MK-4) is negativly associated with VC in patients with CKD. Furthermore, we have previously shown that runt-related transcription factor 2 (Runx2) is important in the phenotypic transformation process of rat vascular smooth muscle cells (VSMCs), which is the key step for the development of VC. The present study investigated the influence of MK-4 on the phenotypic transformation process of rat VSMCs in order to illustrate its role in the process of VC. Calcification assays were perfomed to access the calcified degree of rat VSMCs. Additionally, the genes and proteins related to phenotypic transformation were measured by reverse transcription-polymerase chain reaction and western blotting methods. It was revealed that calcium deposition in the cells was evidently increased with an addition of $\beta$-glycerophosphate $(\beta-\mathrm{GP})$ and could be completely prevented by co-incubation with MK-4 in a dose-dependent manner. Furthermore, the expression of Runx 2 in the $\beta$-GP-induced VSMCs was inhibited by MK-4. It was also revealed that the expression of SMAD1 and bone morphogenetic protein (BMP)-2 were decreased in the $\beta$-GP-induced VSMCs treated with MK-4 in a dose-dependent manner; however, the expression of SMAD7 was increased in the $\beta$-GP-induced VSMCs treated with MK-4 in a dose-dependent manner. These observations suggest that MK-4 reduces mineralization by regulating the BMP-2 signaling pathway in order to attenuate the expression of Runx2.
\end{abstract}

Correspondence to: Dr Jinsheng Xu, Department of Nephrology, The Fourth Hospital of Hebei Medical University, 12 Jiankang Road, Shijiazhuang, Hebei 050011, P.R. China

E-mail: xjs5766@126.com

Key words: menaquinone-4, vascular calcification, runt-related transcription factor 2, bone morphogenetic protein-2, SMAD1, SMAD7

\section{Introduction}

Cardiovascular disease (CVD) is the main cause of mortality in patients with chronic kidney disease (CKD), with a 10-20-fold higher risk compared to the age and sex-matched general population (1). One of the potentially life-threatening cardiovascular (CV) consequences of CKD are vascular calcifications (VCs), which contribute to the high prevalence of CV morbidity and mortality in CKD (2-4). Furthermore, risk factors for the $\mathrm{VC}$ of $\mathrm{CKD}$ patients include abnormal phosphorus and calcium metabolism, bone disorders, phenotype transformation of vascular smooth muscle cells (VSMCs) and deficiency of endogenous calcification inhibitors including Klotho, matrix Gla protein (MGP), pyrophosphate and fetuin-A (5-7).

It has previously been reported that the pathogenesis of $\mathrm{VC}$ is similar to bone formation (8-10). One of the inhibitors of $\mathrm{VC}$ is the vitamin $\mathrm{K}$-dependent protein (VKDPs), MGP, which regulates ectopic mineralization. Vitamin $\mathrm{K}$ functions as a cofactor in the enzymatic reaction that converts specific glutamate residues in MGP into g-carboxyglutamate ones, which are needed for its ability to inhibit calcification (11-13). Furthermore, vitamin $\mathrm{K}$ has the same role in the process of converting growth arrest-specific-6, which can also prevent $\mathrm{VC}$, to their biologically active forms.

Several previous studies have shown that a suboptimal vitamin $\mathrm{K}$ status is common in patients with CKD (14-16). Insufficient levels of vitamin $\mathrm{K}$ result in VKDPs that are functionally inactive and could therefore represent a modifiable risk factor for $\mathrm{VC}$ in $\mathrm{CKD}$ patients. Additionally, vitamin $\mathrm{K}$ is a fat-soluble compound and consists of two natural forms, vitamins $\mathrm{K} 1$ and $\mathrm{K} 2$. Both vitamins function as cofactors for the enzyme $\gamma$-glutamylcarboxylase. Menaquinone (MK)-4 is a member of the vitamin K2 family, and there is data of the Rotterdam study (17) hypothesizing that vitamin $\mathrm{K} 2$ is of greater importance than $\mathrm{K} 1$ for vascular health. Additionally, MK-4 deficiency is a predictor of aortic calcification (18). To the best of our knowledge, there are no previous studies that evaluate the effect of MK-4 on the VSMCs in a $\beta$-glycerophosphate $(\beta$-GP)-induced VC model and the target genes in the regulation of VSMCs differentiation. Therefore, the primary aim of the present study was to investigate how MK-4 inhibited the VC and to characterize the underlying mechanisms. 


\section{Materials and methods}

Cell culture of VSMCs. Rat VSMCs were isolated from the thoracic aorta tunica media of adult male Sprague Dawley rats (Experimental Animal Center of Hebei Medical University, Hebei, China) adopting the method of explant culture as previously described (19). Briefly, the rats were anesthetized by $400 \mathrm{mg} / \mathrm{kg}$ chloral hydrate and sacrificed via cervical dislocation. The thoracic aorta was then removed in gnotobasis. The thoracic aorta was then cut into $1-2 \mathrm{~mm}^{2}$ pieces following the washing off of any residual blood. The tissue pieces were then cultured in dishes with Dulbecco's modified Eagle's medium (DMEM; Gibco; Thermo Fisher Scientific, Inc., Waltham, MA, USA) supplemented with $15 \%$ fetal bovine serum (FBS; Gibco; Thermo Fisher Scientific, Inc.), $4.5 \mathrm{~g}$ glucose, $100 \mu \mathrm{g} / \mathrm{ml}$ streptomycin and $100 \mathrm{U} / \mathrm{ml}$ penicillin in a $5 \% \mathrm{CO}_{2}$ incubator at $37^{\circ} \mathrm{C}$. Cells that migrated from tissue pieces were collected when they reached confluence. Furthermore, the cells were cultured in DMEM replenished with $15 \%$ FBS, and the medium was changed twice per week. VSMCs were identified by positive staining of $\alpha$-smooth muscle actin (Sigma-Aldrich; Merck KGaA, Darmstadt, Germany) and used for all experiments between generations 3-4.

The current study conformed to the Guide for Care and Use of Laboratory Animals as adopted and promulgated by the United National Institutes of Health. All experimental protocols were approved by the Review Committee for the Use of Animal Subjects of Hebei Medical University (Shijiazhuang, China).

Calcification assays. In order to induce calcification, the VSMCs were incubated with a calcifying medium, which consisted of growth medium supplemented with $10 \mathrm{mM}$ $\beta$-GP (Sigma-Aldrich; Merck KGaA). In some experiments, the cells were exposed to calcifying medium accreted with 10, 25 and $50 \mu \mathrm{M}$ of MK-4 (Sigma-Aldrich; Merck KGaA). After incubation for 10 days, the cells were washed twice with phosphate-buffered saline and fixed with $95 \%$ ethanol. Next, the cells were incubated with $0.2 \%$ Alizarin red $[(\mathrm{pH} 8.3)$; Beijing Solarbio Science \& Technology Co., Ltd., Beijing, China]. Subsequent to washing, an LH50A inverted phase contrast microscope (Olympus Corporation, Tokyo, Japan) was used for visualizing cells and capturing images to record the incidence of induced calcification. NIS-Element F3.0 software was used to capture the images (Olympus Corporation). Subsequently, calcium deposited in the extracellular matrix was treated with $0.6 \mathrm{M} \mathrm{HCl}$ for $24 \mathrm{~h}$ at $37^{\circ} \mathrm{C}$, and the content of calcium in the supernatant was measured with the o-cresolphthalein complexone method using a calcium assay kit (BioSino Biotechnology \& Science, Inc., Beijing, China). This was then normalized relative to the protein concentration of the same culture.

Reverse transcription-polymerase chain reaction ( $R T-P C R)$. Total RNA was extracted from VSMCs by reference methods using TRIzol reagent (Invitrogen; Thermo Fisher Scientific, Inc.) in accordance with the manufacturer's instructions, and quantified by an UV absorbance of 260-280 nm. In total, $2 \mu \mathrm{g}$ RNA was used for synthesizing cDNA with the RT-for-PCR kit (Clontech Laboratories, Inc., Mountainview, CA, USA) with oligo (dT) primers as recommended in the protocol provided.
cDNA was used as regular RT-PCR template. Furthermore, the internal control was the glyceraldehyde-3-phosphate dehydrogenase (GAPDH) gene. All of the primers used are listed in Table I. PCR was performed using the PCR Master Mix kit (Promega Corporation, Madison, WI, USA) according to the manusfacturer's protocol and purified prior to sequencing. The PCR conditions were as follows: Initial incubation for $2 \mathrm{~min}$ at $95^{\circ} \mathrm{C} ; 35$ cycles of $30 \mathrm{sec}$ at $95^{\circ} \mathrm{C}$ for denaturation; $30 \mathrm{sec}$ at $55^{\circ} \mathrm{C}$ for annealing; $45 \mathrm{sec}$ at $72^{\circ} \mathrm{C}$ for extension; and a final extension at $72^{\circ} \mathrm{C}$ for $5 \mathrm{~min}$. Cycle sequencing was performed with the Dye Terminator Cycle Sequencing Ready Reaction kit (Applied Biosystems; Thermo Fisher Scientific, Inc.). For regular RT-PCR, the PCR products were detected by a $1.5 \%$ agarose gel with electrophoresis and visualized by staining with ethidium bromide. Furthermore, the reaction of each sample was repeated once for quality control. The optical density of the band was measured using a Gel Documentation System (CST Biological Reagents Co., Ltd., Shanghai, China) and the final data is expressed as the mRNA level relative to that of GAPDH.

Western blot analysis. Total protein was collected from the VSMCs, and the concentrations were measured with the bicinchoninic acid protein assay kit (Sigma-Aldrich; Merck KGaA). Equivalent protein $(50 \mu \mathrm{g})$ from VSMCs were separated by $10 \%$ SDS-PAGE and electrotransferred onto a polyvinylidene fluoride membrane (Amersham; GE Healthcare Life Sciences, Chalfont, UK). Non-specific protein binding was blocked with $5 \%$ non-fat dry milk in Tris-buffered saline and Tween-20 [TBS-T; (20 mmol/1 Tris-HCl (pH 7.6), $150 \mathrm{mmol} / \mathrm{l} \mathrm{NaCl}$ and $0.02 \%$ Tween-20; Invitrogen, Carlsbad, CA, USA] by incubating the membrane for $1 \mathrm{~h}$ at room temperature with agitation. Anti-mouse runt-related transcription factor 2 (Runx2) primary monoclonal antibody (cat. no. ab76956; Abcam, Cambridge, UK) was incubated with the membrane at a 1:500 dilution in TBS-T and at $4^{\circ} \mathrm{C}$ overnight with agitation. The secondary antibody (horesradish perocidase conjugated Goat anti-Mouse Immunoglobulin G; cat. no. 074-1806; KPL, Inc., Gaithersburg, MD, USA) was diluted in TBS-T at 1:2,000 dilution and applied to the membrane, and the reaction was incubated at room temperature for $1 \mathrm{~h}$ with agitation. Between each of the three proceeding steps (primary antibody, secondary antibody and visualization) the membrane was washed 3 times with TBS-T for $15 \mathrm{~min}$ at room temperature. The membrane was then immediately visualized and analyzed using the enhanced chemiluminescence detection system (Santa Cruz Biotechnology, Inc., Dallas, TX, USA) according to the manufacturer's instructions. Furthermore, $\beta$-actin was used as the endogenous control and the experiments were repeated three times.

Statistical analysis. Results are presented as the mean \pm standard deviation, and SPSS 17.0 software (SPSS, Inc., Chicago, IL, USA) was used for the analysis of variance and Dunnett's test. $\mathrm{P}<0.05$ was considered to indicate a statistically significant difference.

\section{Results}

MK-4 attenuates calcification in VSMCs induced by $\beta$-GP. The present study investigated the effects of MK-4 on the 
Table I. Primers used in reverse transcription quantitative polymerase chain reaction.

Primer

\begin{tabular}{lll}
\cline { 2 - 3 } Gene & \multicolumn{1}{c}{ Forward } & Reverse \\
\hline Runx2 & 5'-CCGCACGACAACCGCACCAT-3' & 5'-CGCTCCGGCCCACAAATCTC-3' \\
BMP-2 & 5'-ACTCGAAATTCCCCGTGACC-3' & 5'-CCACTTCCACCACGAATCCA-3' \\
SMAD1 & 5'-GGTGACTGGGAACGGATCG-3' & 5'-TGGTCTTCGGTTCGGAAAGG-3' \\
SMAD7 & 5'-CCTCGGAAGTCAAGAGGCTG-3' & 5'-CCTCGGAAGTCAAGAGGCTG-3' \\
GAPDH & 5'-CAAGGTCATCCATGACAACTTTG-3' & 5'-GTCCACCACCCTGTTGCTGTAG-3'
\end{tabular}

Runx2, runt-related transcription factor 2; BMP-2, bone morphogenetic protein-2.
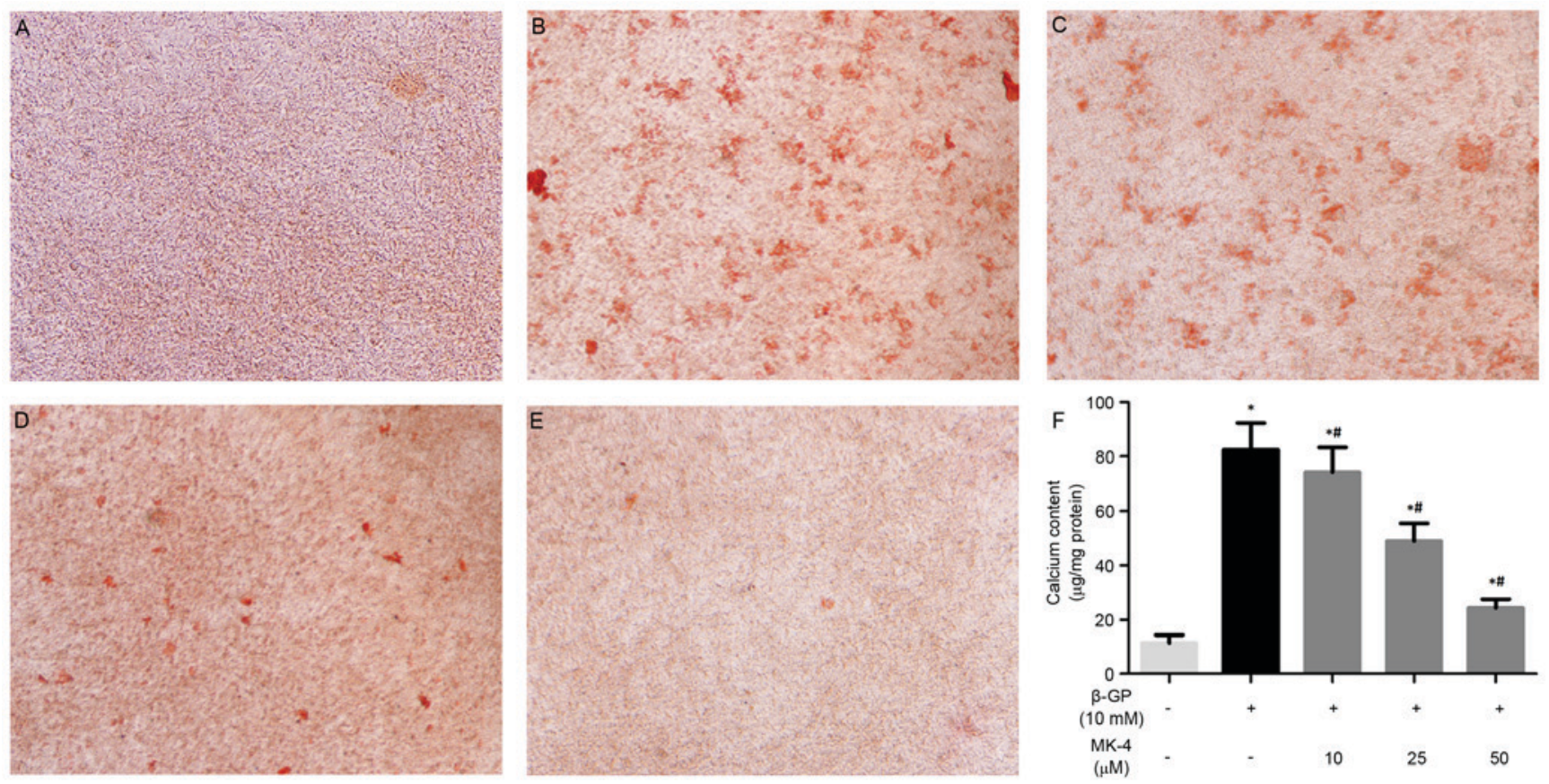

Figure 1. Alizarin red staining was performed on vascular smooth muscle cells incubated under different conditions. (A) control, (B) $\beta$-GP, (C) $\beta$-GP and $10 \mu \mathrm{M}$ MK-4, (D) $\beta$-GP and $25 \mu \mathrm{M}$ MK-4, (E) $\beta$-GP and $50 \mu \mathrm{M}$ MK-4 and (F) calcium content. Magnification, $x 100$. ${ }^{*} \mathrm{P}<0.05$ vs. control; ${ }^{*} \mathrm{P}<0.05$ vs. $\beta$-GP. $\beta$-GP, $\beta$-glycerophosphate; MK-4, menaquinone-4.

calcification of VSMCs induced by $\beta$-GP as previously described (20). MK-4 significantly inhibited calcium deposition of VSMCs induced by $\beta$-GP at 10 days and in a dose-dependent manner (Fig. 1A-E). In agreement, the quantitative analysis indicated that the calcium content was noticeably reduced in VSMCs maintained in the $\beta-\mathrm{GP}+\mathrm{MK}-4$ medium compared with $\beta$-GP medium (Fig. 1F). These results suggest that MK-4 functions in suppressing the calcification of VSMCs induced by $\beta-G P$.

MK-4 inhibits Runx2 expression of VSMCs induced by $\beta-G P$. It has been demonstrated that VSMCs enhanced mineralization under calcifying conditions by phenotype transformation of VSMCs, which is a strictly regulated cellular process that is similar to bone formation (21). Thus, the present study assessed the effects of $\beta$-GP on the expression of Runx 2 in the presence or absence of MK-4 medium. It was revealed that the expression of Runx 2 mRNA and protein in the VSMCs incubated with the $\beta-\mathrm{GP}+\mathrm{MK}-4$ medium evidently decreased, with the effect remaining enhanced in a dose-dependent manner (Fig. 2).

Effects of MK-4 on bone morphogenetic protein-2 (BMP-2), SMAD1, SMAD7 mRNA expression of VSMCs induced by $\beta$-GP. RT-PCR was performed to detect the mRNA expression of BMP-2, SMAD1, SMAD7 in VSMCs induced by $\beta-G P$ in the presence or absence of MK-4. The results revealed that MK-4 significantly reduced BMP-2 and SMAD1 mRNA expression in a dose-dependent manner, while MK-4 markedly increased the expression of SMAD7 mRNA in a dose-dependent manner (Fig. 3). In addition, VSMCs were also treated with $\beta$-GP in the presence or absence of $1 \mathrm{mg} / \mathrm{ml}$ Noggin, which prevents BMP-2 binding to their receptors. As expected, Runx2 expression was upregulated in VSMCs maintained within $\beta$-GP medium compared to the control medium, while the mRNA and protein expression of Runx2 

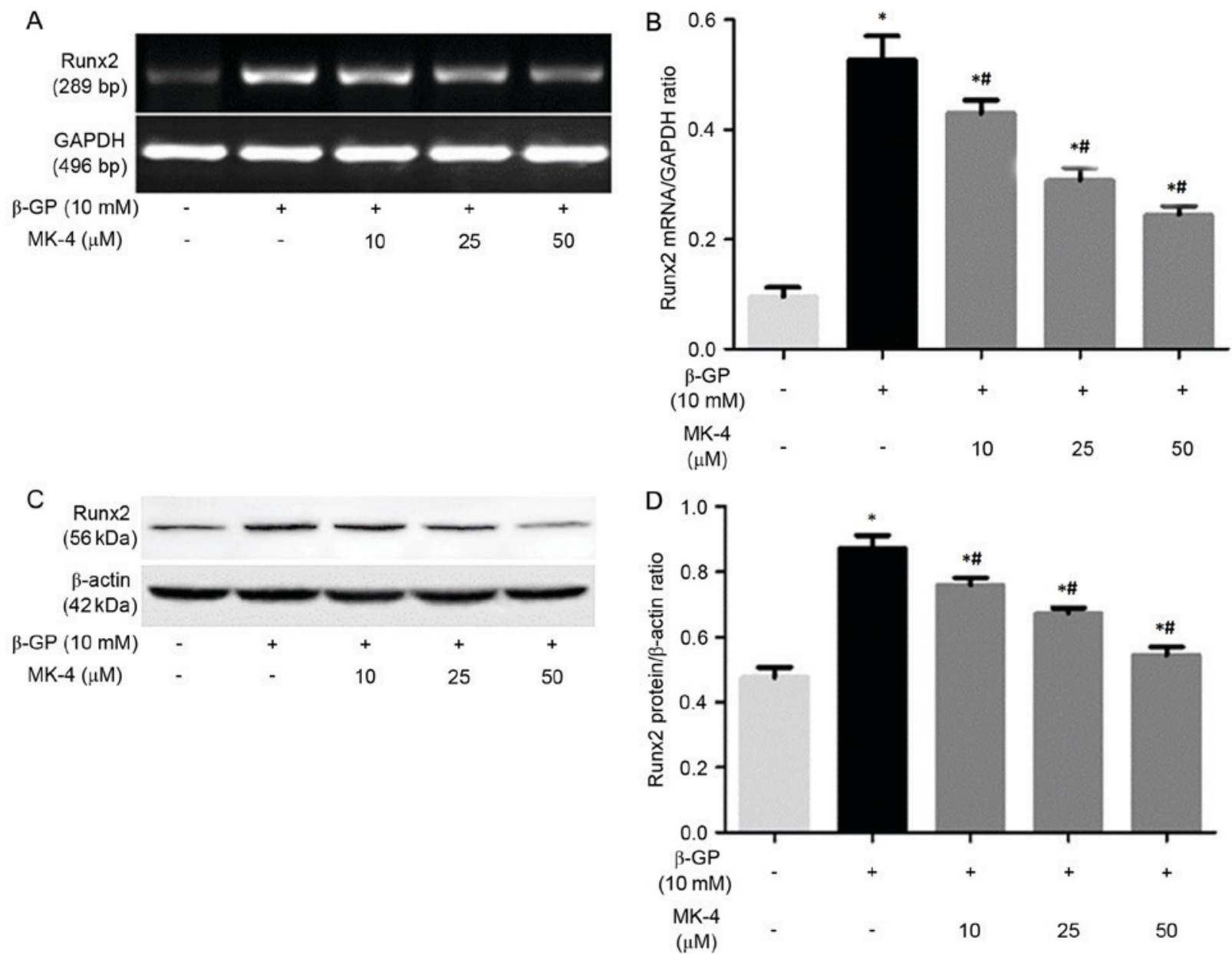

Figure 2. Relative expression levels of Runx 2 mRNA and protein. (A) Representative Runx2 mRNA expression levels from vascular smooth muscle cells following treatment with control medium, $\beta$-GP or $\beta$-GP+MK-4. (B) Quantification of relative expression levels of Runx2. (C) Representative western blots of Runx2 protein in the cells. (D) Quantification of relative protein levels of Runx2. "P<0.05 vs. control; ${ }^{*} \mathrm{P}<0.05$ vs. $\beta$-GP. $\beta$-GP, $\beta$-glycerophosphate; MK-4, menaquinone-4; Runx2, runt-related transcription factor 2; GAPDH, glyceraldehyde 3-phosphate dehydrogenase.

was significantly downregulated $(\mathrm{P}<0.05$; Fig. 4) by noggin. These results indicated that MK-4 partly functions in the modulation of the BMP-2 signaling pathway to inhibit Runx2 expression of VSMCs induced by $\beta-\mathrm{GP}$.

\section{Discussion}

VC is known to be a high risk factor for mortality in CVD, particularly in patients with CKD $(22,23)$. Although numerous studies have demonstrated that a number of factors are involved in regulating $\mathrm{VC}$, an effective therapy has yet to be found. Accumulated evidence manifested that VSMCs to osteoblast-like cell transdifferentiation (VOT) is important in promoting VC $(10,24)$. Furthermore, the change in a variety of key molecules of progression of VOT may promote the occurrence and development of VC. Pharmacological manipulation of signaling pathways or key molecules to inhibit VOT has been sufficient in the treatment of VC (21). Furthermore, a number of studies have indicated that MK-4 was associated with VC (25-27). The present study investigated the effects of MK-4 on the $\beta$-GP-induced calcification processes in rat VSMCs. As predicted, it was identified that adding MK-4 to the medium significantly inhibited calcification induced by $\beta$-GP. Furthermore, the results confirmed that
MK-4 is important in the prevention of the $\beta$-GP-induced calcification of VSMCs, and may prove useful in the treatment of VC.

However, the mechanisms by which MK-4 inhibited the $\mathrm{VC}$ remains unclear. Previous studies have shown that VC is cell-mediated and inactive process, which may result from the osteogenic differentiation of VSMCs and subsequent extracellular matrix mineralization (28-30). Runx2, which is a central transcription factor, is necessary for osteogenic matrix gene expression, bone formation, VSMC calcification and differentiation $(22,31,32)$. Furthermore, the increasing phosphate concentration in vitro results in upregulation of Runx 2 expression and downregulation of smooth muscle-specific gene expression (10). Furthermore, Runx2 has been shown to be expressed in the calcified vascular lesion of CKD patients (33). Thus, Runx2 has been regarded as the earliest and most specific osteogenic marker of differentiation for the promoting calcification. In the present study, the expression of Runx 2 mRNA and protein was evidently upregulated following treatment with $\beta$-GP. However, the upregulated expression of Runx 2 mRNA and protein were inhibited in cells that were co-cultured in a medium with different concentrations of MK-4, with the effect remaining enhanced in a dose-dependent manner. These results 

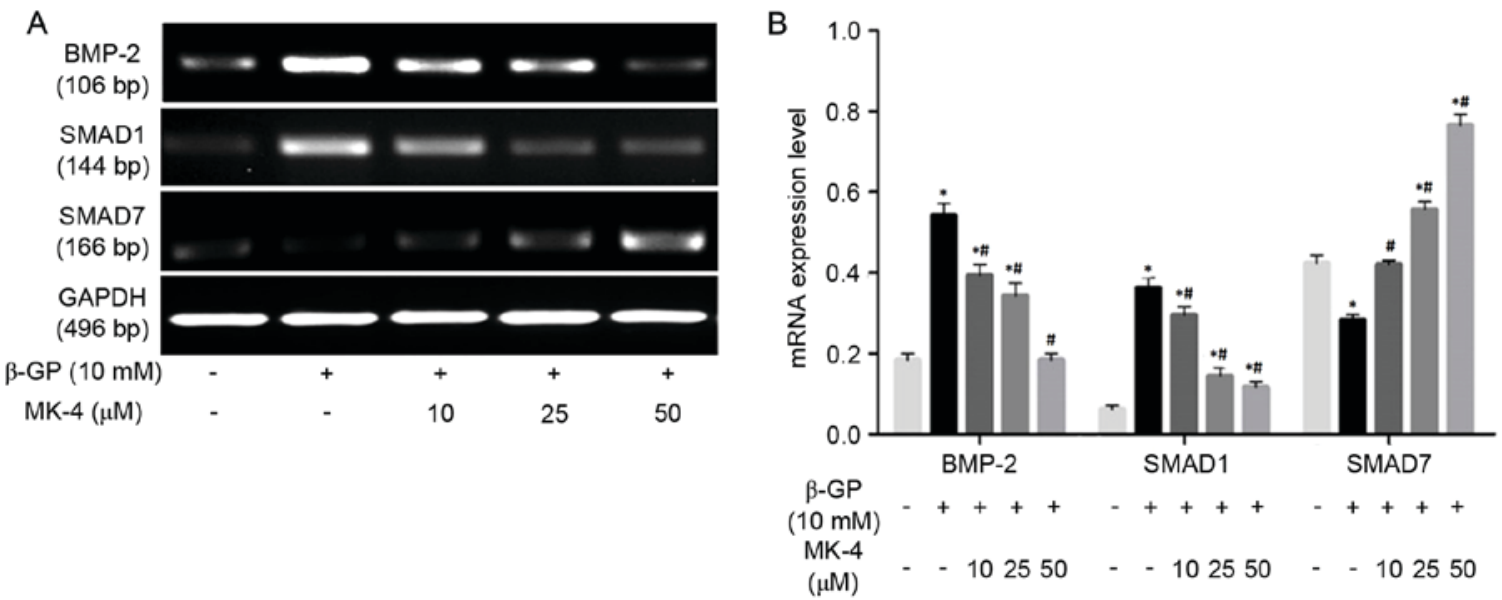

Figure 3. Relative expression levels of BMP-2, SMAD1 and SMAD7 mRNA. (A) Representative mRNA expression following control medium, $\beta$-GP or $\beta$-GP+MK-4. (B) Quantification of the relative mRNA expression levels of BMP-2, SMAD1 and SMAD7. "P $<0.05$ vs. control, ${ }^{\#} \mathrm{P}<0.05$ vs. $\beta$-GP. $\beta$-GP, $\beta$-glycerophosphate; MK-4, menaquinone-4; BMP-2, bone morphogenetic protein-2; GAPDH, glyceraldehyde 3-phosphate dehydrogenase.
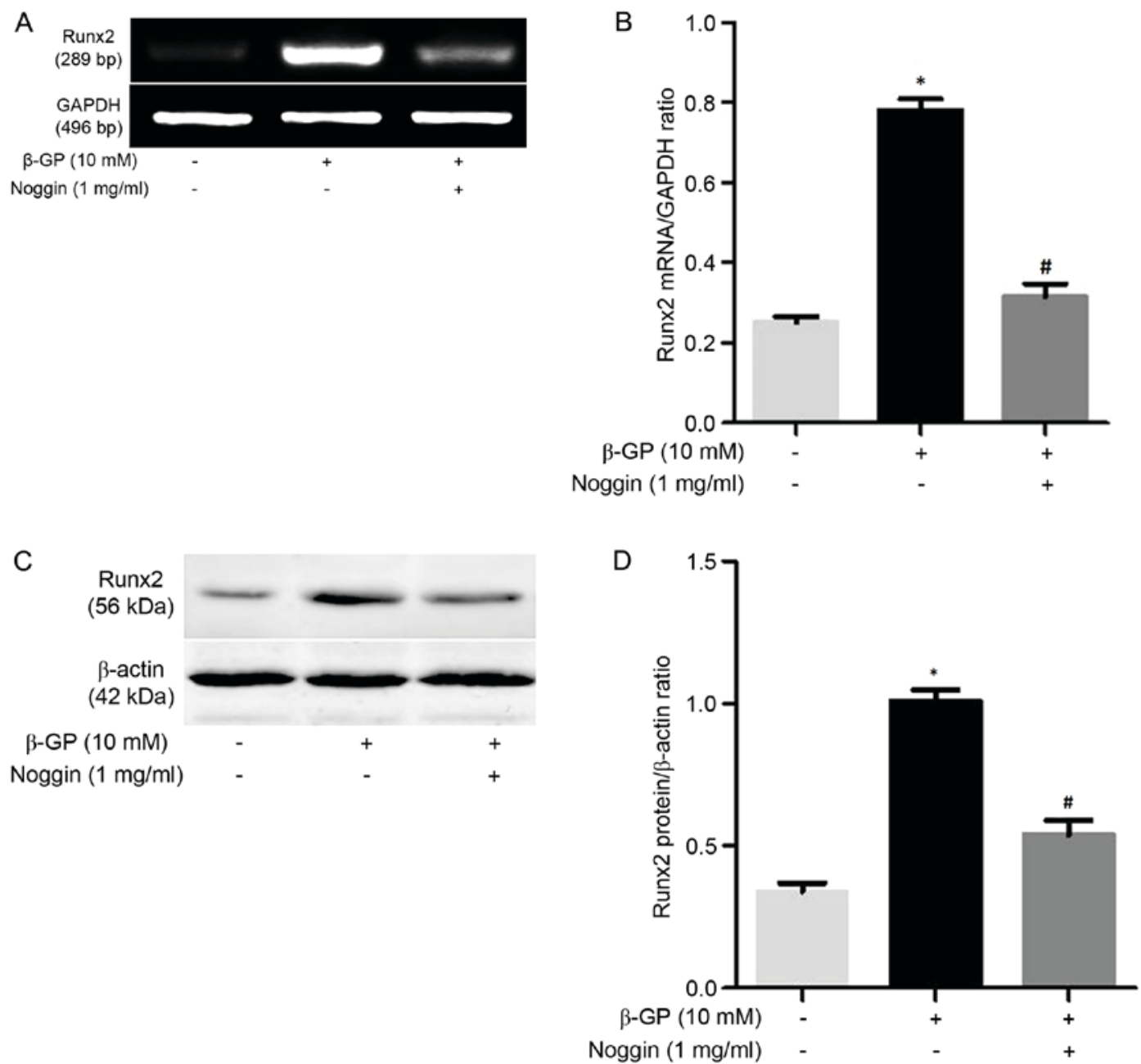

Figure 4. Noggin inhibited $\beta$-GP-induced expression of Runx2. (A) Representative mRNA levels of Runx2 in cells following treatment with $\beta$-GP and $\beta$-GP + noggin. (B) Quantification of the relative mRNA expression levels of Runx2. (C) Representative Western blot analysis of Runx2 in cells following treatment with $\beta$-GP and $\beta$-GP + noggin. (D) Quantification of the relative protein levels of Runx 2 . ${ }^{*} \mathrm{P}<0.05$ vs. control; ${ }^{*} \mathrm{P}<0.05$ vs. $\beta$-GP. $\beta$-GP, $\beta$-glycerophosphate; MK-4, menaquinone-4; Runx2, runt-related transcription factor 2; GAPDH, glyceraldehyde 3-phosphate dehydrogenase.

suggested that MK-4 partly reduced VC by reversing the transdifferentiation of VSMCs in calcifying conditions in a dose-dependent manner.
The BMPs are members of the transforming growth factor- $\beta$ superfamily, and they are important in $\mathrm{VC}$ and bone formation $(34,35)$. Additionally, the BMP subfamily 
can be further subdivided into several subgroups, including BMP-2/4, BMP-5/6/7/8, BMP-5/6/7 and BMP-9/10 (36-38). A number of studies have shown that BMP signaling is a key regulator of vascular disease (39-41). In order to confirm the effect of BMP signaling in $\beta$-GP-induced osteochondrocytic phenotypic change, the effect of Noggin on the Runx2 expression of $\beta$-GP-treated VSMCs was investigated. It was shown that Noggin inhibited the $\beta$-GP-induced Runx2 expression, suggesting that the BMP pathway is involved in $\beta$-GP-induced osteochondrocytic differentiation of rat VSMCs. Next, the present study examined whether the BMP pathway is regulated by MK-4 in VSMCs transdifferentiation induced by $\beta$-GP. The results revealed two things. Firstly, MK-4 inhibited the $\beta$-GP-induced overexpression of BMP-2 and SMAD1, one of the receptor-regulated SMADs (R-SMADs) that form heteromeric complexes with SMAD4 and then these heteromeric R-SMAD/SMAD4 complexes translocate into the nucleus. Secondly, it also increased the $\beta$-GP-regulated down-expression of SMAD7, one of the inhibitory SMADs that antagonize BMP receptor-initiated SMAD signaling by mediating the degradation of receptors and R-SMADs, and suggesting that the inhibitory effect of MK-4 on VSMCs transdifferentiation is mediated, at least in part, through abrogating $\beta$-GP-induced activation of the BMP-2 signaling pathway.

In conclusion, MK-4 was capable of validly reducing calcification induced by $\beta$-GP in rat VSMCs. Furthermore, MK-4 inhibited the transdifferentiation of VSMCs into osteoblast-like cells by suppressing the expression of Runx2 in a dose-dependent manner. In addition, the downregulated expression levels of the inhibitors BMP-2 and SMAD1 and upregulated expression of the promoter SMAD7 caused by MK-4 in a dose-dependent manner was observed. These observations reveal that MK-4 reduces mineralization by the regulation of the signaling pathway of BMP-2 in order to attenuate the expression of Runx2. Furthermore, the present study may help illuminate the function of MK-4 in the calcification of VSMCs induced by $\beta-\mathrm{GP}$.

\section{Acknowledgements}

Not applicable.

\section{Funding}

The present study was supported by the project of the Hebei Natural Science Fund (grant no. H2012206157), the project of the Hebei major medical Science (grant no. GL2011-51) and the project of Hebei Science and Technology Planning (grant no. 16397733D)

\section{Availability of data and materials}

All data are fully available without restriction.

\section{Authors' contributions}

LC, JX, and JZ designed the present study and wrote the manuscript. MZ and SZ performed the statistical analysis. VSMC cell culture, calcification assays, reverse transcription-quantitative polymerase chain reaction and western blotting were performed by SZ and YB.

\section{Ethics approval and consent to participate}

The current study conformed to the Guide for Care and Use of Laboratory Animals as adopted and promulgated by the United National Institutes of Health. All experimental protocols were approved by the Review Committee for the Use of Animal Subjects of Hebei Medical University (Shijiazhuang, China).

\section{Patient consent for publication}

Not applicable.

\section{Competing interests}

The authors declae that they have no competing interests.

\section{References}

1. Tonelli M, Wiebe N, Culleton B, House A, Rabbat C, Fok M, McAlister F and Garg AX: Chronic kidney disease and mortality risk: A systematic review. J Am Soc Nephrol 17: 2034-2047, 2006.

2. Tentori F, Blayney MJ, Albert JM, Gillespie BW, Kerr PG, Bommer J, Young EW, Akizawa T, Akiba T, Pisoni RL, et al: Mortality risk for dialysis patients with different levels of serum calcium, phosphorus, and PTH: The dialysis outcomes and practice patterns study (DOPPS). Am J Kidney Dis 52: 519-530, 2008.

3. Bolasco P: Effects of the use of Non-calcium phosphate binders in the control and outcome of vascular calcifications: A review of clinical trials on CKD patients. Int J Nephrol 2011: 758450, 2011.

4. Adragão T: Evaluation of vascular calcifications in CKD patients. Int J Artif Organs 32: 81-86, 2009.

5. Giachelli CM: The emerging role of phosphate in vascular calcification. Kidney Int 75: 890-897, 2009.

6. Lau WL and Ix JH: Clinical detection, risk factors, and cardiovascular consequences of medial arterial calcification: A pattern of vascular injury associated with aberrant mineral metabolism. Semin Nephrol 33: 93-105, 2013.

7. Olauson $\mathrm{H}$ and Larsson TE: FGF23 and Klotho in chronic kidney disease. Curr Opin Nephrol Hypertens 22: 397-404, 2013.

8. Li X, Yang HY and Giachelli CM: Role of the sodium-dependent phosphate cotransporter, Pit-1, in vascular smooth muscle cell calcification. Circ Res 98: 905-912, 2006.

9. Olszak IT, Poznansky MC, Evans RH, Olson D, Kos C, Pollak MR, Brown EM and Scadden DT: Extracellular calcium elicits a chemokinetic response from monocytes in vitro and in vivo. J Clin Invest 105: 1299-1305, 2000.

10. Steitz SA, Speer MY, Curinga G, Yang HY, Haynes P, Aebersold R, Schinke T, Karsenty G and Giachelli CM: Smooth muscle cell phenotypic transition associated with calcification: Upregulation of Cbfa1 and downregulation of smooth muscle lineage markers. Circ Res 89: 1147-1154, 2001.

11. Schurgers LJ, Uitto J and Reutelingsperger CP: Vitamin K-dependent carboxylation of matrix Gla-protein: A crucial switch to control ectopic mineralization. Trends Mol Med 19: 217-226, 2013.

12. Wallin R, Schurgers LJ and Loeser RF: Biosynthesis of the vitamin K-dependent matrix Gla protein (MGP) in chondrocytes: A fetuin-MGP protein complex is assembled in vesicles shed from normal but not from osteoarthritic chondrocytes. Osteoarthritis Cartilage 18: 1096-1103, 2010.

13. Cranenburg EC, VAN Spaendonck-Zwarts KY, Bonafe L, Mittaz Crettol L, Rödiger LA, Dikkers FG, VAN Essen AJ, Superti-Furga A, Alexandrakis E, Vermeer C, et al: Circulating matrix $\gamma$-carboxyglutamate protein (MGP) species are refractory to vitamin $\mathrm{K}$ treatment in a new case of Keutel syndrome. J Thromb Haemost 9: 1225-1235, 2011.

14. Holden RM, Morton AR, Garland JS, Pavlov A, Day AG and Booth SL: Vitamins K and D status in stages 3-5 chronic kidney disease. Clin J Am Soc Nephrol 5: 590-597, 2010. 
15. Holden RM, Iliescu E, Morton AR and Booth SL: Vitamin K status of Canadian peritoneal dialysis patients. Perit Dial Int 28: 415-418, 2008

16. Westenfeld R, Krueger T, Schlieper G, Cranenburg EC, Magdeleyns EJ, Heidenreich S, Holzmann S, Vermeer C, Jahnen-Dechent W, Ketteler M, et al: Effect of vitamin K2 supplementation on functional vitamin $\mathrm{K}$ deficiency in hemodialysis patients: A randomized trial. Am J Kidney Dis 59: 186-195, 2012.

17. Geleijnse JM, Vermeer C, Grobbee DE, Schurgers LJ, Knapen MH, van der Meer IM, Hofman A and Witteman JC: Dietary intake of menaquinone is associated with a reduced risk of coronary heart disease: The Rotterdam Study. J Nutr 134: 3100-3105, 2004.

18. Koitaya N, Sekiguchi M, Tousen Y, Nishide Y, Morita A, Yamauchi J, Gando Y, Miyachi M, Aoki M, Komatsu M, et al: Low-dose vitamin K2 (MK-4) supplementation for 12 months improves bone metabolism and prevents forearm bone loss in postmenopausal Japanese women. J Bone Miner Metab 32: $142-150,2014$.

19. Campbell JH and Campbell GR: Culture techniques and their applications to studies of vascular smooth muscle. Clin Sci (Lond) 85: 501-513, 1993

20. Chiba Y, Sakai H, Wachi H, Sugitani H, Seyama Y and Misawa M Upregulation of rhoA mRNA in bronchial smooth muscle of antigen-induced airway hyperresponsive rats. J Smooth Muscle Res 39: 221-228, 2003.

21. Zhang S, Xu J, Feng Y, Zhang J, Cui L, Zhang H and Bai Y: Extracellular acidosis suppresses calcification of vascular smooth muscle cells by inhibiting calcium influx via L-type calcium channels. Clin Exp Hypertens 40: 370-377, 2018

22. Xu J, Bai Y, Jin J, Zhang J, Zhang S, Cui L and Zhang $\mathrm{H}$ Magnesium modulates the expression levels of calcification-associated factors to inhibit calcification in a time-dependent manner. Exp Ther Med 9: 1028-1034, 2015.

23. Cherbuin N: Higher dietary intakes of potassium, calcium and magnesium are associated with a reduced risk of developing vascular dementia. Evid Based Ment Health 16: 26, 2013.

24. Chaabane C, Heizmann CW and Bochaton-Piallat ML: Extracellular S100A4 induces smooth muscle cell phenotypic transition mediated by RAGE. Biochim Biophys Acta 1853 2144-2157, 2014

25. Spronk HM, Soute BA, Schurgers LJ, Thijssen HH, De Mey JG and Vermeer C: Tissue-specific utilization of menaquinone-4 results in the prevention of arterial calcification in warfarin-treated rats. J Vasc Res 40: 531-537, 2003.

26. Wahlqvist ML, TanakaK and Tzeng BH:Clinical decision-making for vitamin K-1 and K-2 deficiency and coronary artery calcification with warfarin therapy: Are diet, factor Xa inhibitors or both the answer? Asia Pac J Clin Nutr 22: 492-496, 2013.
27. Koitaya N, Ezaki J, Nishimuta M, Yamauchi J, Hashizume E, Morishita K, Miyachi M, Sasaki S and Ishimi Y: Effect of low dose vitamin K2 (MK-4) supplementation on bio-indices in postmenopausal Japanese women. J Nutr Sci Vitaminol (Tokyo) 55: 15-21, 2009.

28. Kerage D, Brindley DN and Hemmings DG: Review: Novel insights into the regulation of vascular tone by sphingosine 1-phosphate. Placenta 35 (Suppl): S86-S92, 2014.

29. Wang W, Li C, Pang L, Shi C, Guo F, Chen A, Cao X and Wan M: Mesenchymal stem cells recruited by active TGF $\beta$ contribute to osteogenic vascular calcification. Stem Cells Dev 23: 1392-1404, 2014.

30. Danilevicius CF, Lopes JB and Pereira RM: Bone metabolism and vascular calcification. Braz J Med Biol Res 40: 435-442, 2007.

31. Lin ME, Chen T, Leaf EM, Speer MY and Giachelli CM: Runx2 expression in smooth muscle cells is required for arterial medial calcification in mice. Am J Pathol 185: 1958-1969, 2015.

32. Li M, Wu P, Shao J, Ke Z, Li D and Wu J: Losartan inhibits vascular calcification by suppressing the BMP2 and Runx2 expression in rats in vivo. Cardiovasc Toxicol 16: 172-181, 2016.

33. Bai Y, Zhang J, Xu J, Cui L, Zhang H and Zhang S: Alteration of type I collagen in the radial artery of patients with end-stage renal disease. Am J Med Sci 349: 292-297, 2015.

34. Lieberman JR, Daluiski A and Einhorn TA: The role of growth factors in the repair of bone. Biology and clinical applications. J Bone Joint Surg Am 84-A: 1032-1044, 2002.

35. Sun SX, Guo HH, Zhang J, Yu B, Sun KN and Jin QH: BMP-2 and titanium particles synergistically activate osteoclast formation. Braz J Med Biol Res 47: 461-469, 2014.

36. Miyazono K, Kamiya Y and Morikawa M: Bone morphogenetic protein receptors and signal transduction. J Biochem 147: 35-51, 2010.

37. Kawabata M, Imamura $\mathrm{T}$ and Miyazono K: Signal transduction by bone morphogenetic proteins. Cytokine Growth Factor Rev 9: 49-61, 1998.

38. Simoes Sato AY, Bub GL and Campos AH: BMP-2 and -4 produced by vascular smooth muscle cells from atherosclerotic lesions induce monocyte chemotaxis through direct BMPRII activation. Atherosclerosis 235: 45-55, 2014.

39. Yao Y, Bennett BJ, Wang X, Rosenfeld ME, Giachelli C, Lusis AJ and Boström KI: Inhibition of bone morphogenetic proteins protects against atherosclerosis and vascular calcification. Circ Res 107: 485-494, 2010.

40. Cai J, Pardali E, Sánchez-Duffhues G and Ten Dijke P: BMP signaling in vascular diseases. FEBS Lett 586: 1993-2002, 2012.

41. Shao JS, Aly ZA, Lai CF, Cheng SL, Cai J, Huang E, Behrmann A and Towler DA: Vascular Bmp Msx2 Wnt signaling and oxidative stress in arterial calcification. Ann N Y Acad Sci 1117: 40-50, 2007. 